\title{
VHL and HIF-1 $\alpha$ : gene variations and prognosis in early-stage clear cell renal cell carcinoma
}

\author{
Francesca Lessi - Chiara Maria Mazzanti - Sara Tomei - Claudio Di Cristofano • \\ Andrea Minervini - Michele Menicagli • Alessandro Apollo · Lorenzo Masieri • \\ Paola Collecchi · Riccardo Minervini · Marco Carini · Generoso Bevilacqua
}

Received: 17 December 2013/Accepted: 9 January 2014/Published online: 21 January 2014

(C) Springer Science+Business Media New York 2014

\begin{abstract}
Von Hipple-Lindau gene (VHL) inactivation represents the most frequent abnormality in clear cell renal cell carcinoma (ccRCC). Hypoxia-inducible factor- $1 \alpha$ (HIF-1 $\alpha$ ) expression is regulated by $\mathrm{O}_{2}$ level. In normal $\mathrm{O}_{2}$ conditions, VHL binds HIF- $1 \alpha$ and allows HIF- $1 \alpha$ proteasomal degradation. A single-nucleotide polymorphism (SNP) has been found located in the oxygen-dependent degradation domain at codon 582 (C1772T, rs11549465, Pro582Ser). In hypoxia, VHL/HIF-1 $\alpha$ interaction is abolished and HIF- $1 \alpha$ activates target genes in the nucleus. This study analyzes the impact of genetic alterations and protein expression of $V H L$ and the C1772T SNP of HIF-1 $\alpha$ gene $(H I F-1 \alpha)$ on prognosis in early-stage ccRCC (pT1a, pT1b, and pT2). Mutational analysis of the entire VHL sequence
\end{abstract}

F. Lessi $(\varangle) \cdot$ C. M. Mazzanti

Pisa Science Foundation, Via Castaldi, 2, 56100 Pisa, Italy

e-mail: f.lessi@fondazionepisascienza.org

S. Tomei

Department of Genetic Medicine, Weill Cornell Medical College in Qatar, Doha, Qatar

C. Di Cristofano

Department of Experimental Medicine, Sapienza University of Rome, Polo Pontino, I.C.O.T., Latina, Italy

A. Minervini · L. Masieri - M. Carini

Department of Urology, Careggi Hospital, University of Florence, Florence, Italy

M. Menicagli · A. Apollo · P. Collecchi · G. Bevilacqua Division of Surgical, Molecular and Ultrastructural Pathology, Department of Oncology, University Hospital of Pisa, University of Pisa, Pisa, Italy

R. Minervini

Division of Urology, Department of Surgery, University

Hospital of Pisa, University of Pisa, Pisa, Italy and the genotyping of HIF-1 $\alpha$ C1772T SNP were performed together with $V H L$ promoter methylation analysis and loss of heterozygosis ( $\mathrm{LOH})$ analysis at (3p25) locus. Data obtained were correlated with VHL and HIF-1 $\alpha$ protein expression and with tumor-specific survival (TSS). VHL mutations, methylation status, and LOH were detected in 51,11, and $12 \%$ of cases, respectively. Our results support the association between biallelic alterations and/or $V H L$ silencing with a worse TSS. Moreover, we found a significant association between the HIF- $1 \alpha \mathrm{C} 1772 \mathrm{C}$ genotype and a worse TSS. The same association was found when testing the presence of HIF- $1 \alpha$ protein in the nucleus. Our results highlight the role of VHL/HIF- $1 \alpha$ pathway in RCC and support the molecular heterogeneity of earlystage ccRCC. More important, we show the involvement of $H I F-1 \alpha$ C1772T SNP in ccRCC progression.

Keywords Renal carcinoma $\cdot$ VHL $\cdot \mathrm{HIF}-1 \alpha \cdot \operatorname{ccRCC}$

\section{Introduction}

Renal cell carcinoma (RCC) is the most common malignant tumor in the adult kidney, accounting for about $3 \%$ of all human malignancies with the clear cell subtype (ccRCCs) represented $80 \%$ of all RCCs [1].

One of the most common alterations in sporadic ccRCC is the biallelic inactivation of Von Hipple-Lindau gene $(V H L)$ due to mutation, promoter hypermethylation, or loss of heterozygosity $(\mathrm{LOH})$ of chromosome 3p [2, 3].

Von Hipple-Lindau gene is a tumor suppressor gene (TSG) mapping at 3p25-26 and containing three exons [1]. Under normal conditions, the protein encoded by $V H L$, pVHL, localizes preferentially in the cytoplasm maintaining, however, the ability to shuttle between cytoplasm and 
nucleus [4]. pVHL exists in two different isoforms: pVHL30 and pVHL19 [4]. pVHL19 has been shown to contribute to the formation of an ubiquitin ligase (E3) complex (VEC), which controls the proteasomal degradation of several target genes including the hypoxia-inducible factor- $1 \alpha(\mathrm{HIF}-1 \alpha)$ [5]. The ability of pVHL and HIF- $1 \alpha$ to bind each other depends upon the cellular oxygen level. Under normal oxygen conditions, HIF- $1 \alpha$ is hydroxylated in the nucleus on conserved prolyl residues (Pro 402 and Pro 564) within the oxygen-dependent degradation (ODD) domain [6]. Hydroxylated HIF- $1 \alpha$ is able to bind pVHL and such binding allows its polyubiquitination and its consequent degradation [6]. On the contrary, under hypoxic conditions, the non-hydroxylated HIF- $1 \alpha$ cannot bind $\mathrm{pVHL}$ and is free to translocate into the nucleus. Once in the nucleus, HIF- $1 \alpha$ dimerizes with the HIF-1 $\beta$ subunit and trans-activate its target genes [6], which are mainly involved in the resistance to hypoxia, in the glucose uptake and metabolism (Glut1), regulation of extracellular $\mathrm{pH}$ (CAIX), angiogenesis (VEGF), erythropoiesis (EPO), and mitogenesis (PDGF-B) [5].

Von Hipple-Lindau gene alterations suppress the ability of pVHL proteins to bind HIF- $1 \alpha$ causing the constitutive expression of HIF-1 and its inducible genes [7]. Of note, HIF$1 \alpha$ expression has been shown to be high in ccRCC [7].

Von Hipple-Lindau gene inactivation can occur through mutation (approximately $50 \%$ ) [2, 7, 8], hypermethylation (10-20\%) [2, 9], and/or LOH (84-98 \%) at locus 3p25 [10].

In our previous study, we showed that the cytoplasmicnuclear trafficking of pVHL is blocked in ccRCC and the absence of pVHL concurrently associates with a strong HIF-1 $\alpha$ expression [11]. A relatively recent study from

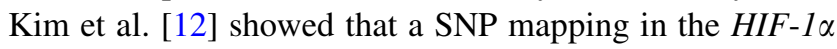
ODD domain (C1772T, rs11549465) associates with HIF$1 \alpha$ protein expression in breast cancer. This SNP leads to a proline to serine substitution at codon 582 [13, 14]. Although $\mathrm{C} 1772 \mathrm{~T}$ has been shown not to affect the hydroxylation process [15], it might confer susceptibility to $\mathrm{RCC}$ and its presence has been demonstrated to correlate with the development of metastases [14]. Here, we evaluated the prognostic significance of such SNP in ccRCC patients. It should be noted that although a growing number of evidence on the molecular alterations underlying ccRCC pathogenesis is currently being accumulated [16], the prognostic relevance of such alterations still lacks of an appropriate investigation. Moreover, contrarily to the majority of the studies already published in the literature, which pool together samples from RCC patients at different stages, we specifically selected a cohort of 136 earlystage ccRCC patients (pT1a, pT1b, and pT2). By simultaneously analyzing clinical samples through direct sequencing, DNA promoter methylation, immunohistochemistry and survival analyses, we show here the ccRCC molecular heterogeneity and evaluate the prognostic significance of $V H L$ and $H I F-1 \alpha$ molecular alterations in this specific subset of early-stage ccRCC patients.

\section{Materials and methods}

\section{Tumor samples}

Formalin-fixed paraffin embedded (FFPE) tissues were collected from a total of 136 intracapsular early-stage ccRCC patients (pT1a, pT1b, and pT2) (mean age 62 year, range 28-85), who underwent radical nephrectomy from 1991 to 2001. Clinical characteristics of this series are reported elsewhere [17]. The evaluation of pathological staging, histotype, nuclear grading, and DNA content was performed as previously described [17].

\section{Tissue microarrays}

Tissue microarrays (TMAs) were established in order to avoid inter-analysis variability during IHC. Core tissue biopsies ( $1 \mathrm{~mm}$ in diameter) were taken from morphologically representative, non-necrotic regions of individual RCC tumor samples and arrayed into new paraffin blocks $\left(45 \times 20 \mathrm{~mm}^{2}\right)$ using Chemicon ATA-100 Tissue Arrayer (Chemicon International Inc., Temecula, CA, USA). Sections of the TMA blocks (5-mm thick) were transferred to glass slides. Each TMA contained 50 tissue cylinders: ten from each of the three primary tumor areas and ten from each of the two paired normal tissues. TMA sections were then deparaffinized and rehydrated.

\section{Immunohistochemistry}

Two commercially available monoclonal pVHL antibodies, clone Ig32 (BD-Bioscience, San Jose, CA, USA) and clone Ig33 (Lab Vision, Kalamazoo, MI, USA), were used at 1:50 and 1:200 dilution, respectively, with clone 32 recognizing both pVHL30 and pVHL19 isoforms and clone 33 specific for pVHL30. A polyclonal anti-HIF-1a antibody (Zymed, Las Condes, Santiago, Chile) was used at 1:50 dilution. The reactions were performed in an automated system (BenchMark XT Ventana, Oro Valley, AZ, USA) and the avidin-biotin peroxidase method was used for visualization. Each IHC analysis was done in duplicate.

$V H L$ sequencing analysis

Von Hipple-Lindau gene sequence was screened for mutations by direct sequencing. Genomic DNA was isolated from FFPE samples, using QIAmp DNA Mini Kit (Qiagen, Germantown, MD, USA), following the manufacturer's instructions. Primers were designed using 
Table 1 Primer sequences

\begin{tabular}{|c|c|}
\hline VHL1a forward & $5^{\prime}$-GGTCTGGATCGCGGAGGGA-3' \\
\hline VHL1a reverse & 5'-GCCCGGCCTCCATCTCCT-3' \\
\hline VHL1b forward & $5^{\prime}$-GCGGAGAACTGGGACGAG-3' \\
\hline VHL1b reverse & 5'-GCGATTGCAGAAGATGACCT-3' \\
\hline VHL1c forward & 5'-GCCGAGGAGGAGATGGAG-3' \\
\hline VHL1c reverse & 5'-GCTTCAGACCGTGCTATCGT-3' \\
\hline VHL2 forward & 5'-AACCTTTGCTTGTCCCGATA-3' \\
\hline VHL2 reverse & 5'-CAGGCAAAAATTGAGAACTGG-3' \\
\hline VHL3 forward & 5'-GATTTGGTTTTTGCCCTTCC-3' \\
\hline VHL3 reverse & 5'-CCATCAAAAGCTGAGATGAAA-3' \\
\hline C1772T forward & 5'-GCTCCCTATATCCCAATGGA-3' \\
\hline $\mathrm{C} 1772 \mathrm{~T}$ reverse & 5'-CAGTGGTGGCAGTGGTAGTG-3' \\
\hline D3S1597 forward & $\begin{array}{l}\text { 5'-CACACAAATGTCTCTCCCTGTG-3' } \\
\text { (FAM) }\end{array}$ \\
\hline D3S1597 reverse & 5'-TCGTTCATTGCTCAAACTCTTT-3' \\
\hline D3S1038 forward & 5'-CACGGGAGTCTACAGCTTGG-3' (FAM) \\
\hline D3S1038 reverse & 5'-TCTGCTCAACTCCCTCCAGT- $3^{\prime}$ \\
\hline
\end{tabular}

Primer3 software (http://frodo.wi.mit.edu/cgi-bin/primer3/ primer3_www.cgi) (Table 1).

PCR was performed using 9700 GeneAmp PCR System (Applied Biosystems, Foster City, CA, USA) following standard procedure: initial denaturation at $95{ }^{\circ} \mathrm{C}$ for $7 \mathrm{~min} ; 40$ cycles at $94^{\circ}$ for $45 \mathrm{~s}$, specific annealing temperature for $45 \mathrm{~s}$, $72{ }^{\circ} \mathrm{C}$ for $1 \mathrm{~min}$; final step at $72{ }^{\circ} \mathrm{C}$ for $10 \mathrm{~min}$. PCR products were purified and labeled using Big Dye terminator kit version 3.1 (Applied Biosystems, Foster City, CA, USA). Sequencing was then performed using Biosystems 3100 Genetic Analyzer (Applied Biosystems, Foster City, CA, USA) and analyzed by sequencing analysis software 3.4 version.

In order to avoid artifacts arising from technical issues, we repeated all the molecular analyses (included the ones described below) 3 times for each samples.

$\mathrm{LOH}$ analysis at locus $3 p$

Loss of heterozygosis was assessed for the D3S1597 and D3S1038 microsatellites located at 3pter-3p24.2 and 3p26.1-3p25.2, respectively.

Primers are reported in Table 1. PCR was performed as described above. PCR products (163 bp length for D3S1597 and 174 bp length for D3S1038) were loaded on ABIPRISM 3100 Genetic Analyzer (Applied Biosystems, Foster City, CA, USA) and analyzed by GeneScan software.

VHL promoter methylation-specific PCR

One $\mu \mathrm{g}$ of genomic DNA was bisulfite-converted using EZ DNA Methylation Kit (Zymo Research Irvine, CA, USA). A positive control was created using human blood treated
Table 2 List of VHL mutations detected in this study

\begin{tabular}{|c|c|c|c|}
\hline Sample & Mutation & Description & Hetero/homo \\
\hline 1 & c. $224 \_225 \mathrm{del}$ & Deletion & Heterozygous \\
\hline 2 & c. $484 \mathrm{~T}>\mathrm{C}$ & Transition & Heterozygous \\
\hline 3 & c. 220_240dup20 & Duplication & Heterozygous \\
\hline 4 & c. $294 \mathrm{del}$ & Deletion & Heterozygous \\
\hline 5 & c. $452 \mathrm{~T}>\mathrm{C}$ & Transition & Heterozygous \\
\hline 6 & c. $416 \mathrm{del}$ & Deletion & Heterozygous \\
\hline 7 & c. $497 \mathrm{~T}>\mathrm{A}$ & Transversion & Heterozygous \\
\hline 8 & c. $509 \mathrm{del}$ & Deletion & Heterozygous \\
\hline 9 & c. $164 \mathrm{del}$ & Deletion & Heterozygous \\
\hline 10 & c. $266 \mathrm{~T}>\mathrm{A}$ & Transversion & Heterozygous \\
\hline 11 & c. $160 \_174 d$ del & Deletion & Heterozygous \\
\hline 12 & c. $494 \mathrm{~T}>\mathrm{A}$ & Transversion & Heterozygous \\
\hline 13 & c. $242 \mathrm{C}>\mathrm{T}$ & Transition & Homozygous \\
\hline 14 & c. $259 \mathrm{G}>\mathrm{A}$ & Transition & Homozygous \\
\hline 14 & c. $343 \mathrm{C}>\mathrm{T}$ & Transition & Homozygous \\
\hline 14 & c. $559 \mathrm{G}>\mathrm{A}$ & Transition & Homozygous \\
\hline 15 & c. $434 \mathrm{del}$ & Deletion & Heterozygous \\
\hline 16 & c. $388 \mathrm{G}>\mathrm{A}$ & Transition & Homozygous \\
\hline 16 & c. $463 \mathrm{G}>\mathrm{A}$ & Transition & Homozygous \\
\hline 17 & c. $221 \mathrm{~T}>\mathrm{A}$ & Transversion & Homozygous \\
\hline 18 & c. $461 \mathrm{C}>\mathrm{T}$ & Transition & Homozygous \\
\hline 18 & c. $625 \mathrm{C}>\mathrm{T}$ & Transition & Heterozygous \\
\hline 19 & c. $424 \mathrm{G}>\mathrm{A}$ & Transition & Homozygous \\
\hline 20 & c. $213 \_233$ dup20 & Duplication & Heterozygous \\
\hline 21 & c. $263 \_270 \mathrm{del}$ & Deletion & Heterozygous \\
\hline 22 & c. $287 \mathrm{del}$ & Deletion & Heterozygous \\
\hline 23 & c. $263 \mathrm{G}>\mathrm{A}$ & Transition & Homozygous \\
\hline 24 & c. $238 \mathrm{~A}>\mathrm{T}$ & Transversion & Heterozygous \\
\hline 24 & c. $239 \mathrm{G}>\mathrm{T}$ & Transversion & Heterozygous \\
\hline 25 & c. $309 \mathrm{del}$ & Deletion & Heterozygous \\
\hline 26 & c. $217 \_225$ dup 8 & Duplication & Heterozygous \\
\hline 27 & c. $343 \mathrm{C}>\mathrm{A}$ & Transversion & Heterozygous \\
\hline 28 & c. $368 \mathrm{G}>\mathrm{A}$ & Transition & Homozygous \\
\hline
\end{tabular}

with CpG Methylase (SssI) (Roche, Basel, Switzerland). PCR amplification was then performed using primers specific for methylated and unmethylated DNA as described by Kuroki et al. [18]. PCR was carried out as described above. PCR products were finally run on a $3 \%$ agarose gel with appropriate size markers.

\section{$H I F-1 \alpha$ C1772T SNP sequencing}

A 178-bp-length PCR region including C1772T SNP was amplified as described above using the primers reported in Table 1. The PCR product was then purified, labeled, and sequenced as described above. 
Statistical analysis

Two-tailed chi-square test was used to assess differences in pVHL and HIF- $1 \alpha$ molecular status and protein expression. Survival probability was estimated by Kaplan-Meier method. All the statistical analyses were performed using MedCalc (MedCalc Software, Ostend, Belgium) and Instat3 software (GraphPad Software, Inc. La Jolla, CA, USA).

\section{Results}

VHL mutational analysis

Von Hipple-Lindau gene mutational analysis was performed in 55 cases out of the 136 samples available. VHL mutations were detected in 28/55 (51\%) ccRCCs. Four additional patients presented multiple mutations. The mutations were located in exon $1(17 / 33,51 \%)$, in exon 2 $(10 / 33,30 \%)$, and in exon $3(6 / 33,18 \%)$. Among the 13/33 (39 \%) truncating mutations, 11 were frameshift and 2 were non-sense mutations. All known mutations detected in this study (Table 2) have been reported previously in the Human Gene Mutation Database (Institute of Medical Genetics in Cardiff: The Human Gene Mutation Database; www.hgmd.cf.ac.uk/ac/) and in the Catalogue of Somatic Mutations in Cancer (COSMIC; www.sanger.ac.uk/genet ics/CGP/cosmic/).

\section{$\mathrm{LOH}$ analysis at VHL locus $3 \mathrm{p}$}

Loss of heterozygosis was assessed in 79 and 75 cases at the marker loci D3S1038 (centromeric to VHL locus) and D3S1597 (telomeric to VHL locus), respectively. Sixty-one cases were informative for D3S1038 and 64 cases were informative for D3S1597. LOH was found in 15/79 (19\%) and 21/75 (28\%) for D3S1038 and D3S1597, respectively. Forty-one cases have been analyzed for both microsatellites. 6/49 (12\%) cases presented LOH in both the markers and 12/49 (24\%) and 19/49 (39\%) cases had D3S1038 and D3S1597 LOH, respectively.

\section{VHL promoter methylation-specific PCR}

Von Hipple-Lindau gene promoter methylation was analyzed in 53 cases. VHL promoter was found methylated in 6/53 (11\%) cases. No case presented promoter methylation in both alleles.

\section{$H I F-1 \alpha \mathrm{C} 1772 \mathrm{~T}$ SNP}

$H I F-1 \propto$ C1772T SNP was genotyped in 117 cases. The $1772 \mathrm{~T}$ allele was present in $35 / 117$ (30\%) cases. The

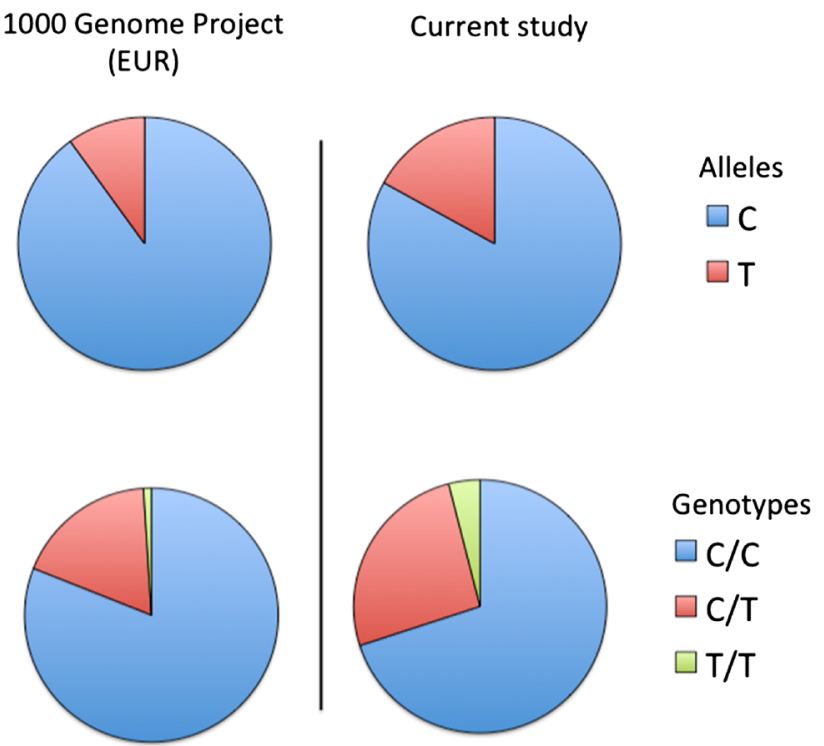

Fig. 1 Pie charts of the allele and genotype frequencies of HIF-1 $\alpha$ C1772T SNP in the EUR populations of the 1000 Genome Project and our cohorts of early ccRCC, respectively

variant allele $(\mathrm{T})$ was present in heterozygosis $(\mathrm{C} / \mathrm{T})$ in $30 / 35(86 \%)$ and in homozygosis (T/T) in 5/35 (14\%).

In order to investigate whether the genotype and allele frequencies of this SNP in our cohort of ccRCC patients differed from the ones reported for healthy individuals in the 1000 Genome Project, we selected the European populations from the 1000 Genome Project dataset (EUR) and compared the genotype and allele frequencies. Concordant to the literature [19], we found a higher T allele and TT genotype frequency in our cohort of ccRCC patients compared with the European healthy subjects from the 1000 Genome Project (Fig. 1), supporting the cancer-predisposing role of the $\mathrm{T}$ allele. Although we acknowledge that a control group should have been recruited from the same population of the ccRCC patients, we believe that the comparison with the 1000 Genome project data provides indication of the potential role of the C1772T SNP in predisposing for $\mathrm{ccRCC}$.

VHL gene variation and protein expression

No significant association was found between VHL mutation, microsatellite, or methylation analysis (taken as singular molecular events) and VHL or HIF-1 $\alpha$ protein expression. Thus, we decided to pool together samples with two alterations (biallelic).

Out of 50 cases analyzed for VHL mutation, $\mathrm{LOH}$ and methylation:

- 16/50 (32\%) cases presented biallelic alterations meant as mutation in homozygosis or as presence at the same 
Table 3 Correlation between biallelic VHL alterations and pVHL expression

\begin{tabular}{llll}
\hline & pVHL + & pVHL- & Total \\
\hline Non-biallelic alterations & 28 & 3 & 31 \\
Biallelic alterations & 13 & 2 & 15 \\
Total & 41 & 5 & 46 \\
\hline
\end{tabular}

$\chi^{2}=0.14, p=0.7$

Table 4 Correlation between HIF- $1 \alpha$ C1772T SNP and the presence of HIF- $1 \alpha$ in the nucleus

\begin{tabular}{llll}
\hline & $\mathrm{C} / \mathrm{T}+\mathrm{T} / \mathrm{T}$ & $\mathrm{C} / \mathrm{C}$ & Total \\
\hline HIF-1 $\alpha$ nucleus + & 11 & 50 & 61 \\
HIF- $1 \alpha$ nucleus - & 15 & 23 & 38 \\
Total & 26 & 73 & 99 \\
\hline
\end{tabular}

$p=0.021$

time of $\mathrm{LOH}$ and mutation, $\mathrm{LOH}$ and methylation or methylation and mutation;

- 15/50 (30\%) cases had only one alteration (mutation, LOH and methylation);

- $19 / 50(38 \%)$ cases carried no alteration.

The association between pVHL expression and the biallelic alteration of $V H L$ was assessed in a total of 46 samples for which all the molecular data were available without reaching statistical significance (Table 3).

HIF- $1 \propto$ C1772C genotype associates with HIF- $1 \alpha$ protein expression

When assessing the association between the HIF-1 $\alpha$ C1772C genotype and HIF- $1 \alpha$ protein expression, we found that the HIF- $1 \alpha$ C1772C homozygous genotype (absence of the pathological variant) significantly associates with a higher HIF-1 $\alpha$ protein nuclear expression $(p=0.021)$ (Table 4).

VHL biallelic variations and tumor-specific survival (TSS)

We then grouped together the normal samples and those with the monoallelic alteration; we found that overall samples carrying biallelic alterations had a worse TSS as compared to samples with no molecular alterations. However, such association did not reach statistical significance (Fig. 2a).

\section{$H I F-1 \alpha \mathrm{C} 1772 \mathrm{~T}$ SNP and TSS}

We further analyzed the correlation between TSS and HIF $1 \alpha$ C1772T SNP. Overall, samples carrying the T/T genotype tended to have a better prognosis as compared to samples carrying the $\mathrm{C} / \mathrm{C}$ and $\mathrm{C} / \mathrm{T}$ genotype (Fig. $2 \mathrm{~b}$ ).

\section{Discussion}

Renal cell carcinoma has been described as made up of several cancers, having different histology and characterized by a different clinical course and response to therapy [20]. The ccRCC subtype accounts for $80 \%$ of sporadic RCCs and can often be cured, if diagnosed on time, and treated when still localized to the kidney (intracapsular) [1]. Overall, intracapsular ccRCCs are known to have a good prognosis. However, 15-20\% of patients might develop recurrence and eventually die for the disease [21].

The inactivation of the VHL tumor suppressor protein and the deregulation of VHL/HIF- $1 \alpha$ axis are common events in ccRCC [5]. The role of pVHL has been extensively studied [5]. pVHL is a multifunctional protein whose function has been clearly linked to kidney carcinogenesis due to its role in the polyubiquitination process. The expression of $\mathrm{pVHL}$ is often found altered in ccRCC due to mutations, promoter methylation and $\mathrm{LOH}$ of the $V H L$.

When assessing the VHL mutational status in our cohort, we found that $V H L$ coding sequence was mutated in $51 \%$ of cases, with exon 1 being the most mutated, as already shown in a previous study [8]. A wide discrepancy exists in literature about the VHL mutation frequency in ccRCC, ranging between 21 and $66 \%$ [22, 23], which may be explained by the different ethnic origin of the populations recruited in the different studies or, more importantly, by the differential efficiency of the technical approaches applied (for example Sanger sequencing is more sensitive than SSCP).

The frequency of VHL LOH at 3p25-26 detected in our study was $11 \%$, which resulted lower than the one reported in the literature [24, 25]. This could be explained by the fact that we analyzed exclusively early-stage intracapsular ccRCCs while other studies grouped together RCC samples at different stages of progression. Thus, it is likely that LOH may be a molecular event, which gradually accumulates during tumor progression.

Von Hipple-Lindau gene promoter was found methylated in $11 \%$ of cases, concordantly to the findings of other studies, which have reported VHL promoter hypermethylation in 7-11\%, cases examined [2,9].

The prognostic relevance of $V H L$ molecular alterations in patients with sporadic ccRCCs remains to be established. Few studies have addressed the issue of clinical impacts of somatic VHL alterations in sporadic RCCs reporting, however, conflicting results $[2,15,26]$. Brauch et al. [2] have showed a significant association between VHL alterations (mutation and methylation) and advanced RCC 
Fig. 2 Kaplan-Meier curves of samples carrying no and biallelic alterations (a) and carrying T1772T, C1772T, and C1772C genotypes
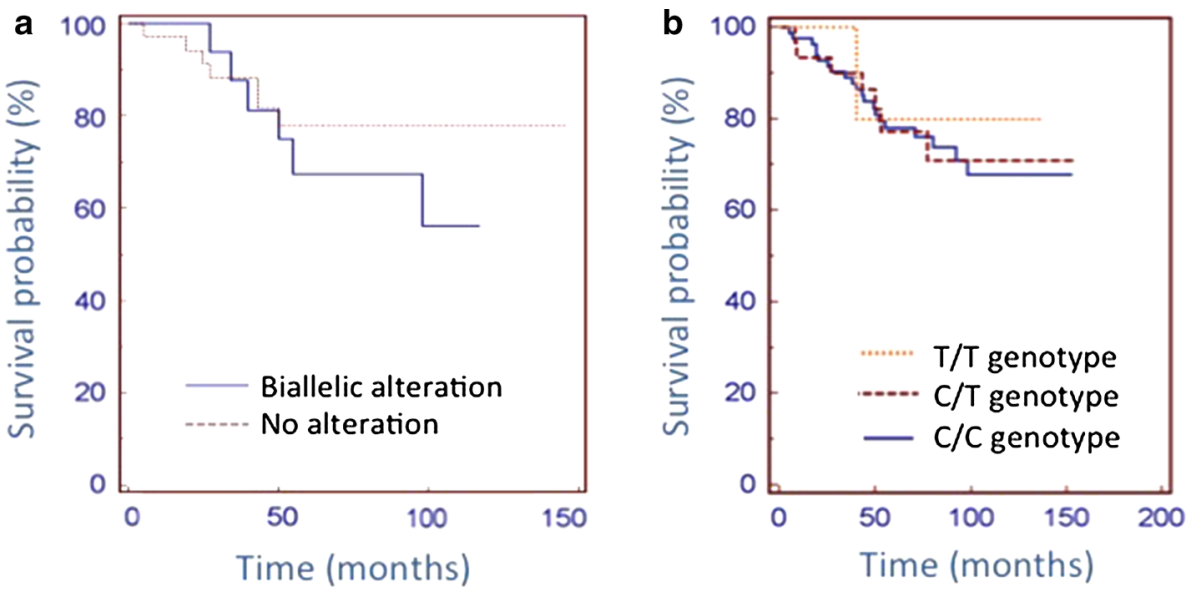

tumor stage. Similarly, Schraml et al. [27] showed that ccRCC with $V H L$ open reading frame mutations, which potentially lead to pVHL loss of function, are associated with a worse prognosis. Kondo et al. [26], in another study, were not able to find any significant association between $V H L$ alteration and disease prognosis.

When assessing here the clinical impact of $V H L$ molecular alterations on the prognosis, we found that overall patients with biallelic $V H L$ alterations had a shorter TSS, supporting the relevance of VHL in RCC carcinogenesis. However, this association did not reach statistical significance, maybe because the casuistic recruited was not large enough to allow the detection of statistical significance. Larger sample size studies are warranted to exploit this issue.

No association between VHL mutation, methylation and LOH analysis taken as a singular molecular event and TSS was found in this study, supporting the VHL function as TSG. Indeed, TSGs generally require multiple inactivation events to loose their function, according to the two-hits Knudson hypothesis.

Another important player in RCC development is $H I F$ $1 \alpha$. HIF- $1 \alpha$ resides on chromosome $14 \mathrm{q}$, whose homozygous deletion leads to absent protein production [28]. In some cases, alternative mRNA splicing around deleted $H I F-1 \alpha$ exonic sequence leads to the production of aberrant HIF-1 $\alpha$ isoforms [28]. Although rare, intragenic $H I F-1 \alpha$ mutations, including missense mutations, have been described in clear renal carcinoma tumors [28]. Besides mutational events, inherited polymorphisms might also play a role in RCC carcinogenesis. A common SNP mapping in the ODD domain in exon 12 of HIF-1 $\alpha$ (C1772T, Pro582Ser) has been described in the literature [13, 29]. Although not involved in the process of hydroxylation [14], this SNP may confer susceptibility to renal cancerogenesis and progression. Supporting this hypothesis, Kim et al. [8] showed that the Pro582Ser change contributes to the development of metastases. When comparing the distribution of this SNP in our cohort with the 1000 Genome Project data, we found that the $\mathrm{T}$ allele frequency was higher in the ccRCC patients compared with the healthy subjects. Moreover, when correlating the different C1772T genotypes with the HIF-1 $\alpha$ protein nuclear expression, we found the $\mathrm{C} / \mathrm{C}$ genotype to be associated with a higher nuclear protein expression $(p=0.021)$. Conversely, samples carrying the T/T genotype did not express HIF-1 $\alpha$ in the nucleus. Not surprisingly, heterozygous samples had $50 \%$ presence and $50 \%$ absence of the nuclear HIF-1 $\alpha$ protein expression. These data suggest that the $\mathrm{C} 1772 \mathrm{~T}$ SNP may influence the HIF-1 $\alpha$ nuclear expression or, likely, the recruitment of transcriptional cofactors may be enhanced or suppressed depending on the specific allele through conformational changes caused by amino acid substitution. Studies aiming at assessing the functional role of this SNP on the protein nuclear localization are required to exploit this intriguing association.

When assessing the genotype association with TSS, quite surprisingly, we found that the T/T genotype overall associated with a better TSS (Fig. 2b), suggesting that carrying the $\mathrm{T}$ allele in homozygosis may determine an advantage in terms of prognosis. The mechanisms behind this phenomenon are not known. We are currently undertaking studies to exploit this association.

\section{Conclusions}

In conclusion, our study provides insights about the molecular alteration of VHL/HIF-1 $\alpha$ axis in early-stage ccRCC and show the potential role of $H I F-1 \alpha$ C1772T SNP in affecting HIF- $1 \alpha$ protein nuclear expression. Additional functional studies are, however, required to unmask the mechanisms underlying such association. 
Conflict of interest None.

\section{References}

1. Ficarra V, Schips L, Guille F, Li G, De La Taille A, Prayer Galetti T, et al. Multiinstitutional European validation of the 2002 TNM staging system in conventional and papillary localized renal cell carcinoma. Cancer. 2005;104(5):968-74. doi:10.1002/ cncr. 21254

2. Brauch H, Weirich G, Brieger J, Glavac D, Rodl H, Eichinger M, et al. VHL alterations in human clear cell renal cell carcinoma: association with advanced tumor stage and a novel hot spot mutation. Cancer Res. 2000;60(7):1942-8.

3. Foster K, Crossey PA, Cairns P, Hetherington JW, Richards FM, Jones $\mathrm{MH}$, et al. Molecular genetic investigation of sporadic renal cell carcinoma: analysis of allele loss on chromosomes $3 \mathrm{p}, 5 \mathrm{q}$, 11p, 17 and 22. Br J Cancer. 1994;69(2):230-4.

4. Iliopoulos O, Ohh M, Kaelin WG Jr. pVHL19 is a biologically active product of the von Hippel-Lindau gene arising from internal translation initiation. Proc Natl Acad Sci USA. 1998; 95(20):11661-6.

5. Shen C, Kaelin WG Jr. The VHL/HIF axis in clear cell renal carcinoma. Semin Cancer Biol. 2013;23(1):18-25. doi:10.1016/j. semcancer.2012.06.001.

6. Ivan M, Kondo K, Yang H, Kim W, Valiando J, Ohh M, et al. HIFalpha targeted for VHL-mediated destruction by proline hydroxylation: implications for $\mathrm{O}_{2}$ sensing. Science. 2001;292(5516): 464-8. doi:10.1126/science.1059817.

7. Gnarra JR, Tory K, Weng Y, Schmidt L, Wei MH, Li H, et al. Mutations of the VHL tumour suppressor gene in renal carcinoma. Nat Genet. 1994;7(1):85-90. doi:10.1038/ng0594-85.

8. Kim JH, Jung CW, Cho YH, Lee J, Lee SH, Kim HY, et al. Somatic VHL alteration and its impact on prognosis in patients with clear cell renal cell carcinoma. Oncol Rep. 2005;13(5):859-64.

9. Graff JR, Herman JG, Myohanen S, Baylin SB, Vertino PM. Mapping patterns of $\mathrm{CpG}$ island methylation in normal and neoplastic cells implicates both upstream and downstream regions in de novo methylation. J Biol Chem. 1997;272(35):22322-9.

10. Clifford SC, Prowse AH, Affara NA, Buys CH, Maher ER. Inactivation of the von Hippel-Lindau (VHL) tumour suppressor gene and allelic losses at chromosome arm $3 p$ in primary renal cell carcinoma: evidence for a VHL-independent pathway in clear cell renal tumourigenesis. Genes Chromosom Cancer. 1998;22(3):200-9.

11. Di Cristofano C, Minervini A, Menicagli M, Salinitri G, Bertacca G, Pefanis G, et al. Nuclear expression of hypoxia-inducible factor-1alpha in clear cell renal cell carcinoma is involved in tumor progression. Am J Surg Pathol. 2007;31(12):1875-81. doi:10.1097/PAS.0b013e318094fed8.

12. Kim HO, Jo YH, Lee J, Lee SS, Yoon KS. The C1772T genetic polymorphism in human HIF-1alpha gene associates with expression of HIF-1alpha protein in breast cancer. Oncol Rep. 2008;20(5):1181-7.

13. Ollerenshaw M, Page T, Hammonds J, Demaine A. Polymorphisms in the hypoxia inducible factor-1alpha gene (HIF1A) are associated with the renal cell carcinoma phenotype. Cancer Genet Cytogenet. 2004;153(2):122-6. doi:10.1016/j.cancergencyto.2004.01.014.

14. Percy MJ, Mooney SM, McMullin MF, Flores A, Lappin TR, Lee FS. A common polymorphism in the oxygen-dependent degradation (ODD) domain of hypoxia inducible factor-1alpha (HIF1alpha) does not impair Pro-564 hydroxylation. Mol Cancer. 2003;2:31. doi:10.1186/1476-4598-2-31.
15. Yao M, Yoshida M, Kishida T, Nakaigawa N, Baba M, Kobayashi $\mathrm{K}$, et al. VHL tumor suppressor gene alterations associated with good prognosis in sporadic clear-cell renal carcinoma. J Natl Cancer Inst. 2002;94(20):1569-75.

16. Sato Y, Yoshizato T, Shiraishi Y, Maekawa S, Okuno Y, Kamura $\mathrm{T}$, et al. Integrated molecular analysis of clear-cell renal cell carcinoma. Nat Genet. 2013;45(8):860-7. doi:10.1038/ng.2699.

17. Minervini A, Di Cristofano C, Collecchi P, Salinitri G, Selli C, Bevilacqua $G$, et al. Intracapsular clear cell renal carcinoma: ploidy status improves the prognostic value of the 2002 TNM classification. J Urol. 2005;174(4 Pt 1):1203-7 Discussion 7.

18. Kuroki T, Trapasso F, Yendamuri S, Matsuyama A, Alder H, Mori $\mathrm{M}$, et al. Allele loss and promoter hypermethylation of VHL, RAR-beta, RASSF1A, and FHIT tumor suppressor genes on chromosome $3 p$ in esophageal squamous cell carcinoma. Cancer Res. 2003;63(13):3724-8.

19. Hu X, Fang Y, Zheng J, He Y, Zan X, Lin S, et al. The association between HIF-1alpha polymorphism and cancer risk: a systematic review and meta-analysis. Tumour Biol. 2013; doi:10. 1007/s13277-013-1160-x.

20. Linehan WM, Vasselli J, Srinivasan R, Walther MM, Merino M, Choyke P, et al. Genetic basis of cancer of the kidney: diseasespecific approaches to therapy. Clin Cancer Res. 2004;10(18 Pt 2):6282S-9S. doi:10.1158/1078-0432.CCR-050013.

21. Minervini A, Lilas L, Minervini R, Selli C. Prognostic value of nuclear grading in patients with intracapsular (pT1-pT2) renal cell carcinoma. Long-term analysis in 213 patients. Cancer. 2002;94(10):2590-5.

22. Gimenez-Bachs JM, Salinas-Sanchez AS, Sanchez-Sanchez F, Lorenzo-Romero JG, Donate-Moreno MJ, Pastor-Navarro H, et al. Determination of VHL gene mutations in sporadic renal cell carcinoma. Eur Urol. 2006;49(6):1051-7. doi:10.1016/j.eururo. 2005.10.028.

23. Igarashi H, Esumi M, Ishida H, Okada K. Vascular endothelial growth factor overexpression is correlated with von HippelLindau tumor suppressor gene inactivation in patients with sporadic renal cell carcinoma. Cancer. 2002;95(1):47-53. doi:10. 1002/cncr.10635.

24. Sukosd F, Kuroda N, Beothe T, Kaur AP, Kovacs G. Deletion of chromosome 3p14.2-p25 involving the VHL and FHIT genes in conventional renal cell carcinoma. Cancer Res. 2003;63(2):455-7.

25. Velickovic M, Delahunt B, Storkel S, Grebem SK. VHL and FHIT locus loss of heterozygosity is common in all renal cancer morphotypes but differs in pattern and prognostic significance. Cancer Res. 2001;61(12):4815-9.

26. Kondo K, Yao M, Yoshida M, Kishida T, Shuin T, Miura T, et al. Comprehensive mutational analysis of the VHL gene in sporadic renal cell carcinoma: relationship to clinicopathological parameters. Genes Chromosom Cancer. 2002;34(1):58-68.

27. Schraml P, Struckmann K, Hatz F, Sonnet S, Kully C, Gasser T, et al. VHL mutations and their correlation with tumour cell proliferation, microvessel density, and patient prognosis in clear cell renal cell carcinoma. J Pathol. 2002;196(2):186-93. doi:10. 1002/path.1034.

28. Shen C, Beroukhim R, Schumacher SE, Zhou J, Chang M, Signoretti $\mathrm{S}$, et al. Genetic and functional studies implicate HIF1alpha as a $14 \mathrm{q}$ kidney cancer suppressor gene. Cancer Discov. 2011;1(3):222-35. doi:10.1158/2159-8290.CD-11-0098.

29. Tanimoto K, Yoshiga K, Eguchi H, Kaneyasu M, Ukon K, Kumazaki T, et al. Hypoxia-inducible factor-1alpha polymorphisms associated with enhanced transactivation capacity, implying clinical significance. Carcinogenesis. 2003;24(11):1779-83. doi:10.1093/car cin/bgg132. 